\title{
High strain rate compression testing of glass fibre reinforced polypropylene
}

\author{
R.A. Govendera , G.S. Langdon, T.J. Cloete, and G.N. Nurick \\ Blast Impact and Survivability Research Unit, Department of Mechanical Engineering, University of Cape Town, \\ Private Bag X3, Rondebosch 7701, South Africa
}

\begin{abstract}
This paper details an investigation of the high strain rate compression testing of GFPP with the Split Hopkinson Pressure Bar (SHPB) in the through-thickness and in-plane directions. GFPP posed challenges to SHPB testing as it fails at relatively high stresses, while having relatively low moduli and hence mechanical impedance. The modifications to specimen geometry and incident pulse shaping in order to gather valid test results, where specimen equilibrium was achieved for SHPB tests on GFPP are presented. In addition to conventional SHPB tests to failure, SHPB experiments were designed to achieve specimen equilibration at small strains, which permitted the capture of high strain rate elastic modulus data. The strain rate dependency of GFPP's failure strengths in the in-plane and through-thickness direction is modelled using a logarithmic law.
\end{abstract}

\section{Introduction}

Glass fibre reinforced polypropylene (GFPP) is a thermoplastic composite used in diverse applications such as car bumpers [1], boat hulls and wind turbine blades [2]. Fibre reinforced polymers (FRP) based on thermoplastics such as polypropylene are being investigated as replacements for thermoset based FRPs, due to the improved toughness and impact resistance of the more ductile matrix (Hufenbach et al [3]). As impact loading is likely in all of the above applications, knowledge of the rate dependent properties of GFPP is of interest to designers. The published strain rate dependent data on GFPP was investigated in detail by Govender [4]. Rate dependency studies of GFPP have been published by Hufenbach et al [3] and Brown et al [5], but these are generally limited to strain rates $\dot{\varepsilon} \leq 10^{2} / \mathrm{s}$. No Split Hopkinson Pressure Bar (SHPB) test data on GFPP has been published to date, which is surprising as the SHPB is the generally accepted means of material testing at high strain rates $\left(\dot{\varepsilon} \approx 10^{2}\right.$ to $\left.10^{4} / \mathrm{s}\right)$. This study presents data from compression SHPB testing of GFPP.

\section{Experimental method}

\subsection{Specimen details}

GFPP panels were produced from Twintex $\AA^{\circledR} 2 \times 2$ twill weave frabric, which results in a nominal fibre volume fraction of $35 \%$ [6]. Panels of $300 \mathrm{~mm} \times 300 \mathrm{~mm}$ were fabricated by laying up Twintex $₫$ fabric in a mould, which was heated in an oven till a mid-plane temperature of $185^{\circ} \mathrm{C}$ was reached and maintained for 20 minutes. The mould was then transferred to a cold press and consolidated under a pressure of 1.2 MPa. Panels consisting of 25 and 44 plies were manufactured, resulting in nominal panel thicknesses of 12 and $20 \mathrm{~mm}$. The measured density of the GFPP was $1450 \mathrm{~kg} / \mathrm{m}^{3}$.

\footnotetext{
a e-mail: reuben.govender@uct.ac.za
}

All specimens were cut from the panels using abrasive water jet cutting, and were polished using 220 and 500 grit $\mathrm{SiC}$ polishing paper. For both quasi-static and SHPB tests, the specimen faces in contact with the loading platens or bars were lubricated with molybdenum grease. Cylindrical specimens of nominal diameter $11 \mathrm{~mm}$ were cut from the $12 \mathrm{~mm}$ thick panel for through-thickness testing. Cubic specimens of width and breadth $11 \mathrm{~mm}$ were cut from the $12 \mathrm{~mm}$ thick panel for in-plane testing.

Cubic specimens of nominal width and breadth $20 \mathrm{~mm}$ were cut from the $20 \mathrm{~mm}$ thick panel, for determining the through-thickness modulus. These specimens were instrumented with $120 \Omega, 2 \mathrm{~mm}$ gauge length strain gauges.

\subsection{Quasi-static tests}

Quasi-static tests were conducted on a Zwick ${ }^{\mathrm{TM}} 1484$ Universal Test Frame, by compressing the specimens between polished, hardened steel anvils. Tests were conducted at $0.1,1.0$ and $10 \mathrm{~mm} / \mathrm{min}$ cross-head speeds, with a minimum of five specimens tested at each speed, in the throughthickness and in-plane directions.

\subsection{Split Hopkinson pressure bar tests}

High strain rate compression tests were conducted using a Split Hopkinson Pressure Bar (SHPB) apparatus. The bars were centerless ground silver steel (nominal elastic limit of $600 \mathrm{MPa}$ ) of $20 \mathrm{~mm}$ diameter and nominal length $2000 \mathrm{~mm}$. The output bar was $50 \mathrm{~mm}$ shorter than the input bar - this ensures that the tensile reflected wave in the output bar unloads the specimen before the second transit of the wave in the input bar arrives, thus preventing repetitive loading of the specimen. The bars were instrumented with a pair of diametrically oppposed $120 \Omega, 2 \mathrm{~mm}$ gauge length strain gauges at the mid-length of the bars. The strain gauge bridge excitation voltage was $5 \mathrm{~V}$, with the output voltage amplified by a gain of 1000 and recorded on a 12 bit data recorder at $10 \mathrm{MHz}$. The measured density $\rho$ of the 
bars was $7850 \mathrm{~kg} / \mathrm{m}^{3}$ and the wave speed $C_{o}$ was initially measured to be $5105 \mathrm{~m} / \mathrm{s}$. In order to reduce variation in the strain rate during specimen loading, conical strikers were employed to generate a non-trapezoidal input wave, which is discussed in greater detail in Cloete and van der Westhuizen [7] and Govender et al [8]. The striker had a uniform taper from a back face diameter of $24 \mathrm{~mm}$ down to a front (impact) face diameter of $18 \mathrm{~mm}$ over a length of $400 \mathrm{~mm}$.

Forces and velocities at the specimen faces of the input and output bars were calculated from the usual SHPB equations, details of which may be found in Gray [9] or Song and Chen [10]:

$$
\begin{gathered}
F_{\text {in }}=A_{\text {in }} E_{\text {in }}\left(\varepsilon_{i}(t)+\varepsilon_{r}(t)\right) \\
v_{\text {in }}=-C_{\text {o(in })}\left(\varepsilon_{i}(t)-\varepsilon_{r}(t)\right) \\
F_{\text {out }}=A_{\text {out }} E_{\text {out }} \varepsilon_{t}(t) \\
v_{\text {out }}=-C_{\text {o(out })} \varepsilon_{t}(t)
\end{gathered}
$$

Where the subscripts in, out refer to the input and output bar respectively, $A$ is the cross-sectional area, $E$ elastic modulus and the subscripts $i, r, t$ refer to the incident, reflected and transmitted waves respectively. The waves captured at the strain gauge stations are shifted to the bar faces using the method described in Follansbee and Frantz [11] and Gorham [12], which accounts for dispersion of the waves. Given the initial specimen length $l_{o}$, the velocities are integrated to find instantaneous specimen length $l_{s}(t)$, which is then used to calculate true (logarithmic) strain. By assuming that the specimen volume remains constant, the instantaneous specimen area $A_{s}(t)$ can be calculated from the original area $A_{o}$ and length $l_{o}$, which permits calculation of the true specimen stress $\sigma_{t}(t)$ based on the force at the output face $F_{\text {out }}$.

\subsection{Through-thickness modulus tests}

Cubic specimens of $20 \mathrm{~mm}$ thickness were instrumented with pairs of strain gauges on opposite faces, aligned in the through-thickness direction, in order to measure the through-thickness elastic modulus. To complete the strain gauge Wheatstone bridge, dummy gauges were mounted on similar blocks of GFPP to eliminate any temperature effects. For quasi-static tests, the specimens were subjected to cyclic loading between forces of $300 \mathrm{~N}$ and $2 \mathrm{kN}$, corresponding to nominal specimen stresse of 0.75 and $5 \mathrm{MPa}$ which are well below the stresses at which any damage accumulates. The cyclic tests were conducted at cross-head speeds of $1 \mathrm{~mm} / \mathrm{min}$.

It is usually very difficult to extract modulus data from SHPB tests, as during the early part of the test (when the specimen is deforming elastically) the forces at the input and output faces have not reached dynamic equilibrium. As the specimens for modulus determination were of similar cross sectional area to the bars, the impedance mismatch was reduced, which reduces the time required
Table 1. Summary of through-thickness compression results for GFPP.

\begin{tabular}{lccccc}
\hline Rate & $\begin{array}{c}0.1 \\
\mathrm{~mm} / \mathrm{min}\end{array}$ & $\begin{array}{c}1.0 \\
\mathrm{~mm} / \mathrm{min}\end{array}$ & $\begin{array}{c}10 \\
\mathrm{~mm} / \mathrm{min}\end{array}$ & $\mathrm{SHPB}$ & DIHPB \\
\hline$\sigma_{t}(\mathrm{MPa})$ & 242.2 & 256.0 & 271.3 & 313.8 & 293.5 \\
$\begin{array}{l}\text { Std. Dev. } \\
\text { (MPa) }\end{array}$ & 11.9 & 7.9 & 18.0 & 16.7 & 20.9 \\
C.O.V $(\%)$ & $4.9 \%$ & $3.1 \%$ & $6.6 \%$ & $5.3 \%$ & $7.1 \%$ \\
$\dot{\varepsilon}(/ s)$ & $1.4 \times 10^{-4}$ & $1.4 \times 10^{-3}$ & $1.4 \times 10^{-2}$ & $5.3 \times 10^{2}$ & $1.2 \times 10^{3}$ \\
\hline
\end{tabular}

for equilibration. The rise time of the incident wave was increased by judicious use of putty between the striker and input bar. By increasing the rise time, the likelihood of equilibration was increased at the cost of lowering the nominal strain rate.

\subsection{Direct impact Hopkinson pressure bar tests}

Direct Impact Hopkinson Pressure Bar (DIHPB) tests were conducted to extend the strain rate range over which data was obtained. DIHPB testing is discussed in detail by Gorham et al $[13,14]$. The same HPB as used as the input bar for the SHPB tests was used for the DIHPB tests. The striker used for the DIHPB tests was cut from the same stock as used for the HPB, to ensure that HPB and striker impedances were matched. The force acting on the specimen is determined using Eq. (3). In DIHPB tests, forces on the impact and output faces of the specimen are assumed to be in equilibrium. When using a striker which has the same impedance and area as the HPB with a measured impact velocity $V_{s}$, the instantaneous specimen length $l_{s}(t)$ is then determined from [14]:

$$
l_{s}(t)=l_{o}-V_{s} t+\int_{0}^{t} \frac{2 E_{y}}{C_{o} \rho} \varepsilon_{t}(\tau) d \tau
$$

The specimen true stress and strain are then calculated in the same manner as for a SHPB test.

\section{Results}

\subsection{Through-thickness failure strength}

The quasi-static true stress-strain response was linear until an abrupt failure. The results of the quasi-static throughthickness failure tests are summarised in Table 1. Photographs of specimens showing the observed failure modes are shown in Fig. 1, but are not discussed for brevity, as this paper focusses on the SHPB tests. An important criteria for valid SHPB testing is that the stresses at the input and output faces of the specimen achieve quasi-equilibrium. Initial SHPB tests to failure in the through-thickness direction did not achieve acceptable equilibration, as shown in Fig. 2. The stress at the output face of the specimen is lower than the stress at the input face throughout the loading, and at the peak stress the difference is approximately $72 \mathrm{MPa}$ $(24 \%)$. Various systemic causes of the lack of equilibration were considered: 


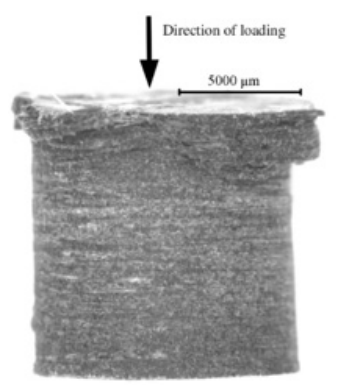

(a)

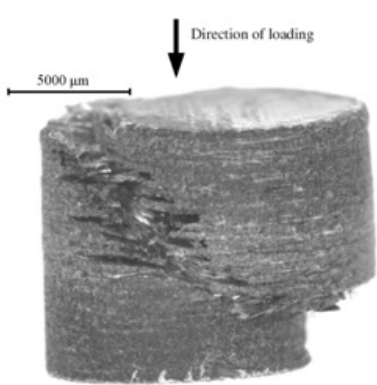

(b)
Fig. 1. Through-thickness compression specimens exhibiting (a) spreading failure and (b) macroscopic shear.

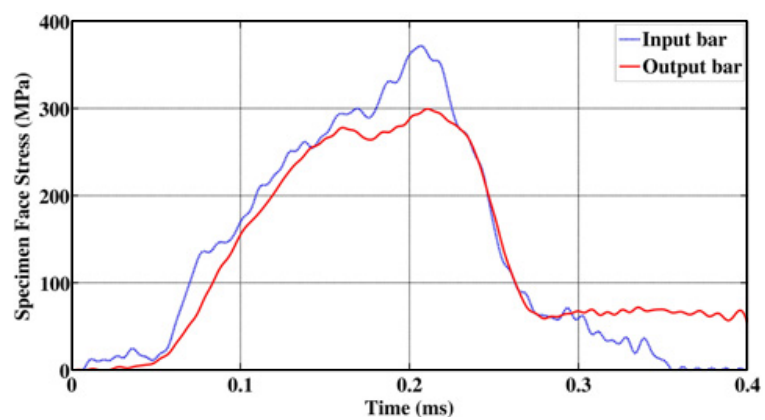

Fig. 2. Specimen face stresses during SHPB through-thickness failure test, showing poor equilibration.

Lifshitz and Leber [15] noted that small variations between the wave speed used in the calculation and the actual wave speed can manifest as an offset of the waves when the waves are shifted from the gauges to the bar faces. This offset can be perceived as a lack of equilibrium. Further measurements of the wave speeds showed that the input bar had $C_{o}=5120 \mathrm{~m} / \mathrm{s}$, while that of the output bar was correct at $5105 \mathrm{~m} / \mathrm{s}$. However, the slightly faster wave speed in the input bar results in a smaller time shift, which results in the input face stress rising faster which exacerbates the lack of equilibrium. Furthermore, there is a different not just in offset of the input and output face stresses, but in the magnitudes of peak stress. The magnitude of the stress waves is strongly dependent on the calibration constants used to convert the strain gauge bridge output voltages to bar stresses. This calibration constant was determined experimentally and independently for the input and output bars: each bar in turn was impacted with a striker of the same material and diameter with the impact velocity $V_{s}$ measured. Under these conditions, the magnitude of the approximately trapezoidal stress wave in the bar is given by $[9,10]$ :

$$
\sigma_{i n c}=\frac{1}{2} \rho C_{o} V_{s}
$$

The calibration factor is hence the ratio of $\sigma_{i n c}$ and the magnitude of the plateau of the measured strain gauge bridge output voltage $V_{B r}$. The calibration factors were independently determined for the input and output bars. While the calibration factor of the output bar was higher than that of the input bar, the difference was less than $1 \%$, which cannot account for the 20 to $25 \%$ difference seen across the first set of tests.

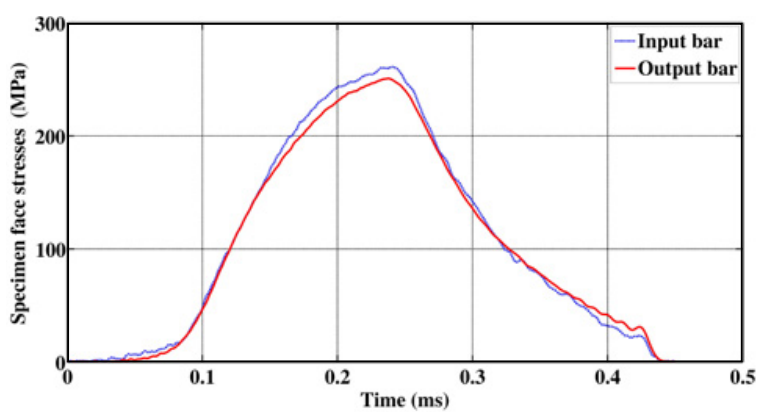

Fig. 3. Specimen face stresses for modified specimen geometry, showing good equilibration.

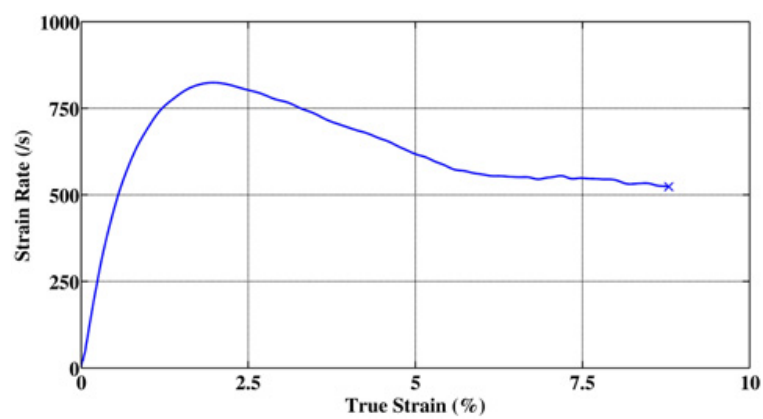

Fig. 4. Strain rate for a typical SHPB test using a conical striker.

It was noted that the diameter of the specimens was approximately half that of the bars. This was chosen to ensure that the stresses in the bars would remain well below the elastic limit, despite the relatively high failure stresses in the specimens. However, the difference in diameters also causes a mismatch in mechanical impedance. GFPP has a relatively low modulus $\left(E_{33} \approx 2 G P A-\right.$ see Sec. 3.2) and hence has very low characteristic impedance $\rho C_{o}=1.7 \mathrm{MPa} \mathrm{s} / \mathrm{m}$, in comparison to the steel bars where $\rho C_{o}=40 \mathrm{MPas} / \mathrm{m}$. The large difference in characteristic impedance of the GFPP specimens and steel bars will hinder equilibration, and this is exacerbated by the large difference in areas. The large impedance mismatch was addressed by changing the specimen geometry. The specimen diameter was increased from 11 to $15 \mathrm{~mm}$, which reduced the area mismatch and hence the number of wave transits to approach equilibrium as discussed by Yang and Shim [16]. The specimen thickness was reduced from 11 to $6 \mathrm{~mm}$. This reduced the specimen wave transit time, which reduced the total time to approach equilibrium. The specimen face streses for the modified geometry are shown in Fig. 3. There is good agreement between the input and output face stresses, with the difference in peak stresses being $10 \mathrm{MPa}(4 \%)$ which was considered acceptable. The strain rate as a function of specimen true strain for a typical test using a conical striker is shown in Fig. 4. While the strain rate is does decrease from a peak of $8.2 \times 10^{2}$ to $5.2 \times 10^{2} / \mathrm{s}$ at failure, this variation is far less than that reported in other publications on SHPB testing of FRPs (for example Tarfaoui et al [17] or Gama et al [18]).

The results of all the quasi-static, SHPB and DIHPB tests are provided in Table 1 , with $\sigma_{t}$ representing the peak true stress. The failure modes of the SHPB and DIHPB 


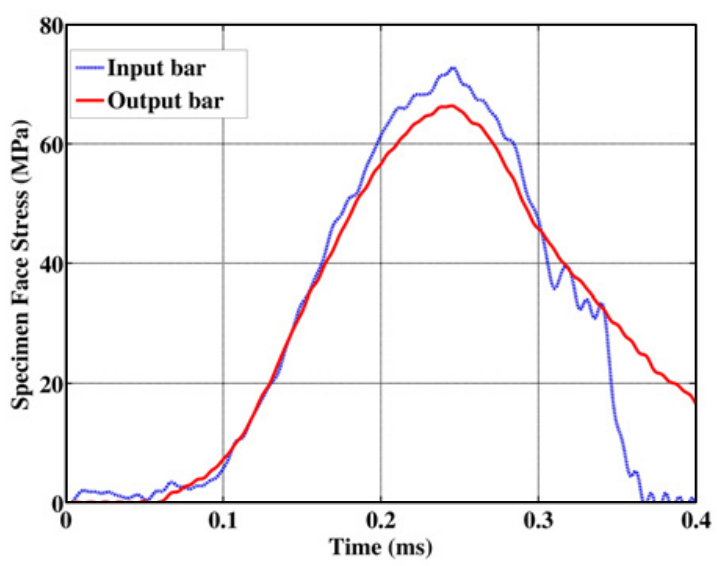

Fig. 5. Specimen face stresses during SHPB modulus test.

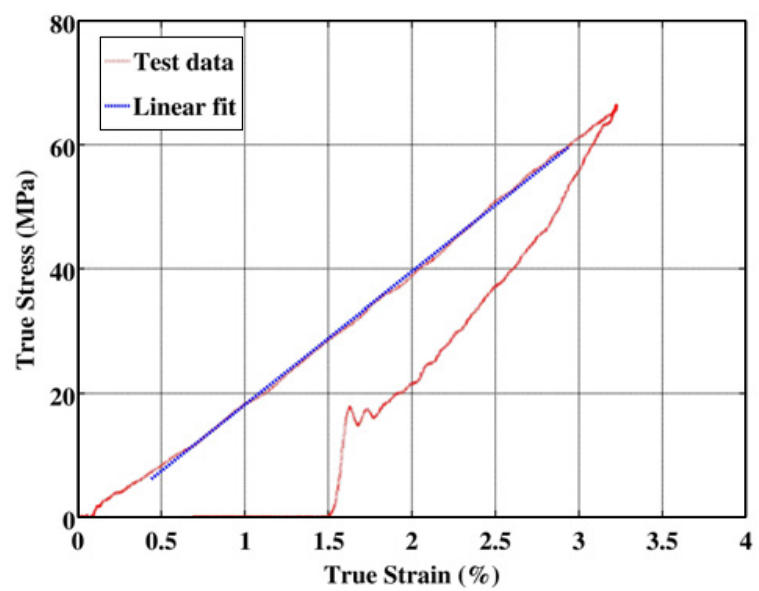

Fig. 6. Linear fit to SHPB data for modulus estimation.

tests presented no significant differences to the quasi-static failure modes.

\subsection{Through-thickness modulus}

The quasi-static through-thickness modulus $\left(E_{33}\right)$ tests resulted in a measured modulus of $1.9 \mathrm{GPa}$ at a strain rate $\dot{\varepsilon}=1.4 \times 10^{-3} / \mathrm{s}$.

The input and output face stresses for a SHPB modulus test are shown in Fig. 5. It is clear that the face stresses have reached quasi-equilibrium between stresses of 10 and $40 \mathrm{MPa}$. Above $40 \mathrm{MPa}$, the stresses diverge as the specimen begins to unload - however, this data is not included in the linear fit used to estimate $E_{33}$. The linear fit to the true stress-true strain data for a typical test is shown in Fig. 6, with an average value of $2.48 \mathrm{GPa}$ obtained across six tests. The strain rate as a function of true strain for a typical test is shown in Fig. 7, with the average strain rate for the SHPB modulus tests being $\dot{\varepsilon}=1.5 \times 10^{2} / \mathrm{s}$.

In order to characterise the rate dependency of the modulus, more data is required. This would entail Dynamic Mechanical Analysis (DMA) at low $(\dot{\varepsilon} \leq 1 / s)$ strain rates and highly specialised test frames for intermediate $(1<\dot{\varepsilon} \leq 100 / s)$ strain rates, which is left for future work.

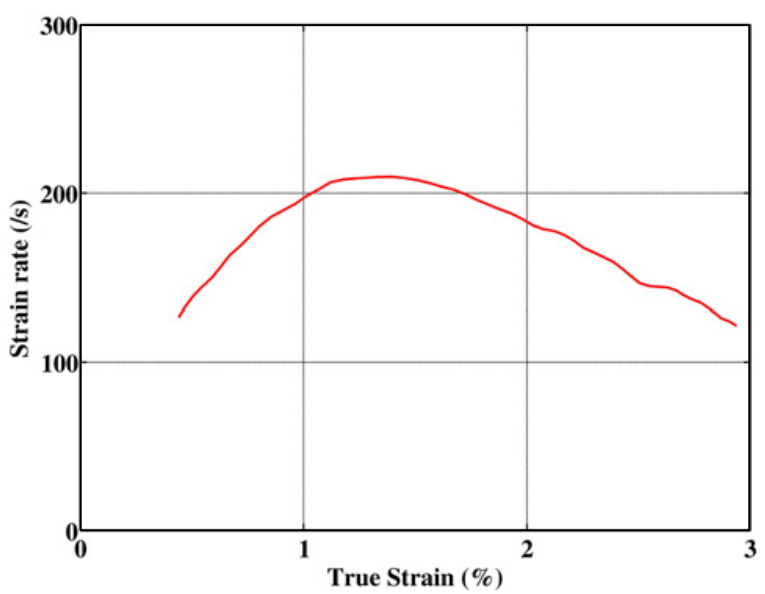

Fig. 7. Strain rate during SHPB through-thickness modulus test.

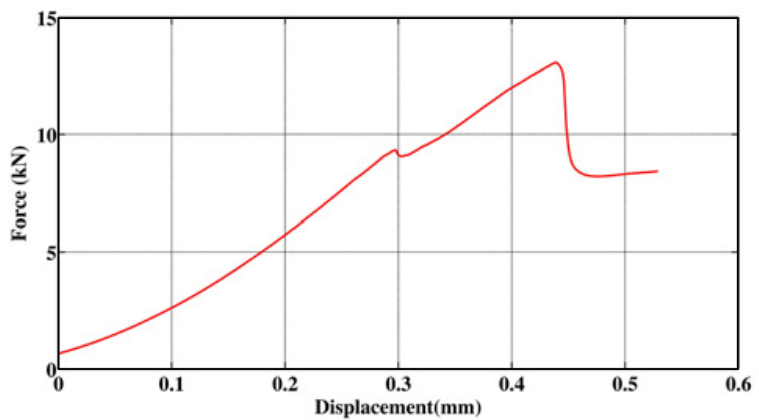

Fig. 8. Force-displacement curve for a typical quasi-static inplane compression test on GFPP.

\subsection{In-plane failure strength}

The force deflection curve for a typical quasi-static inplane compression test on GFPP is shown in Fig. 8. The small drop in force coincided with observation of brooming of the loaded surfaces and fibre kinking, while the final catastrophic failure was associated with large scale delamination as shown in Fig. 9. The results of the quasistatic in-plane failure tests are presented in Table 2. As the brooming and delamination failures make a constant volume assumption questionable, the results are presented in terms of engineering stress $\left(\sigma_{e n g}\right)$. As with the initial through-thickness SHPB tests, the in-plane SHPB tests did not result in acceptable equilibration, despite the refinements to the data analysis discussed in Sec. 3.2. Typical data for the specimen input and output face stresses are shown in Fig. 10. At the peak stress the difference is $20 \mathrm{MPa}(12.5 \%)$ but during the increase in stress the difference is as much as $60 \%$, which is not acceptable. It was not possible to reduce the length of the in-plane specimens (in order to reduce the wave transit time), as this would have made the specimen smaller than one representative volume of the weave pattern. Further investigation using HPB with less of an impedance mismatch (for example polymeric bars) is left for future work. The in-plane SHPB results are included in Table 2, with a cautionary note that the validity of the results is yet to be confirmed. 
Table 2. Summary of in-plane compression results for GFPP.

\begin{tabular}{lccccc}
\hline Rate & $\begin{array}{c}0.1 \\
\mathrm{~mm} / \mathrm{min}\end{array}$ & $\begin{array}{c}1.0 \\
\mathrm{~mm} / \mathrm{min}\end{array}$ & $\begin{array}{c}10 \\
\mathrm{~mm} / \mathrm{min}\end{array}$ & $\mathrm{SHPB}$ & DIHPB \\
\hline$\sigma_{\text {eng }}(\mathrm{MPa})$ & 108.8 & 112.0 & 133.9 & 160.6 & 189.8 \\
Std. Dev. & 5.5 & 3.9 & 7.4 & 17.2 & 6 \\
$\quad(\mathrm{MPa})$ & & & & & \\
C.O.V $(\%)$ & $5.1 \%$ & $3.5 \%$ & $5.5 \%$ & $10.7 \%$ & $3.6 \%$ \\
$\dot{\varepsilon}(/ s)$ & $1.6 \times 10^{-4}$ & $1.6 \times 10^{-3}$ & $1.6 \times 10^{-2}$ & $5.7 \times 10^{2}$ & $1.1 \times 10^{3}$ \\
\hline
\end{tabular}

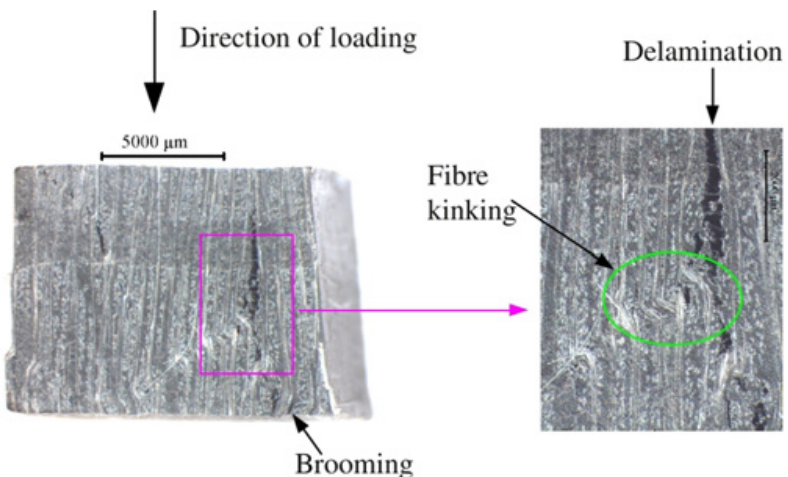

Fig. 9. Typical failed specimen after quasi-static in-plane compression test on GFPP.

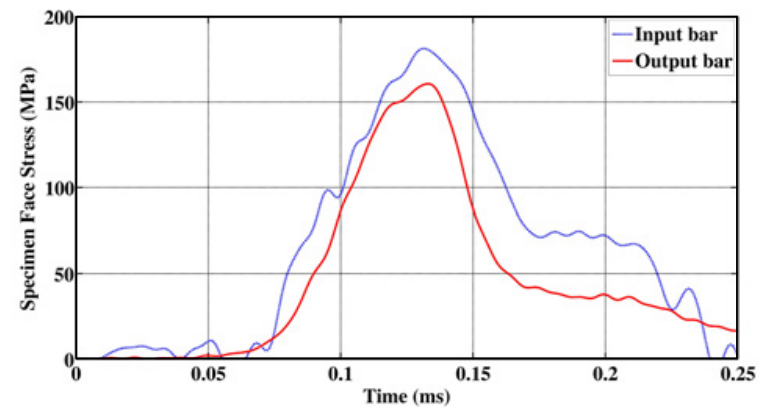

Fig. 10. Specimen face stresses during SHPB in-plane failure test, showing poor equilibration.

\section{Discussion and concluding remarks}

The aim of most high rate material characterisation exercises is to provide data for rate dependent models. The available data is used to fit a logarithmic strain rate model (for example $[3,5,19]$ ), of the form:

$$
\sigma=\sigma_{o}\left[1+c \ln \left(\frac{\dot{\varepsilon}}{\dot{\varepsilon}_{o}}\right)\right]
$$

The reference strain rate $\dot{\varepsilon}_{o}$ is chosen to be unity in this analysis. Due to the questions surrounding the inplane SHPB data, this data was excluded when fitting the parameters, but is plotted for completeness. The model parameters for the through-thickness and in-plane strength are presented in Table 3, with the data fitting shown in Figs. 11 and 12.

Compression tests of GFPP in the through thickness and in-plane directions showed that the peak stress increases with strain rate. Through thickness failure modes were either spreading failure at the loaded faces, or macroscopic shear. In order to achieve acceptable equilibrium
Table 3. Logarithmic model parameters.

\begin{tabular}{lcc}
\hline Parameter & Through-thickness & In-plane \\
\hline$\sigma_{o}(M P a)$ & 280 & 152.7 \\
$c$ & 0.013 & 0.035
\end{tabular}

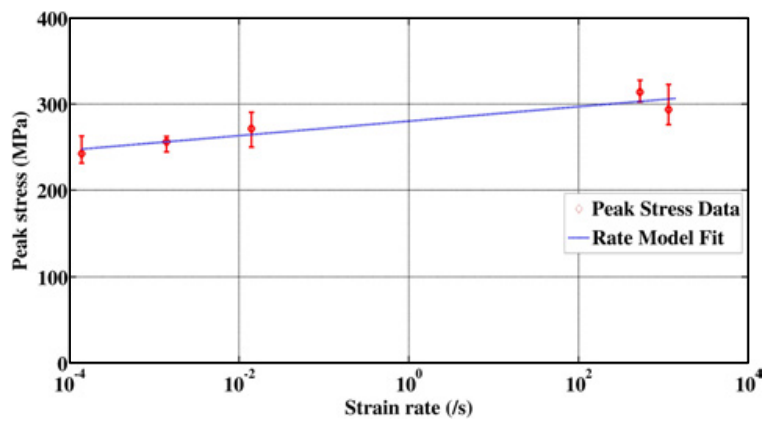

Fig. 11. Strain rate dependence of through-thickness compressive strength.

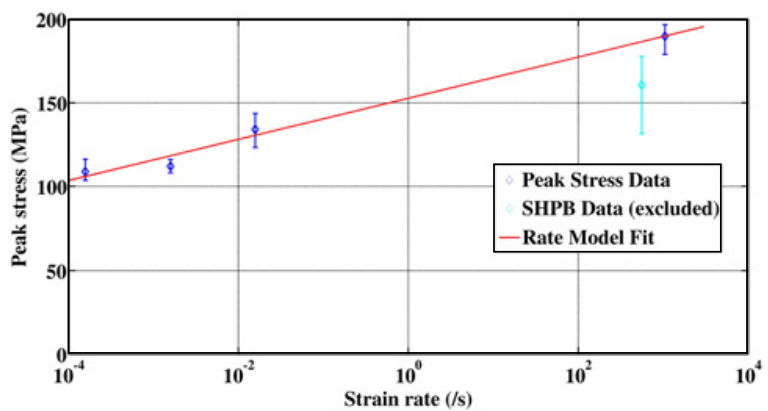

Fig. 12. Strain rate dependence of through-thickness compressive strength.

for the through-thickness tests, some modification of specimen geometry was required. This reduced the impedance mismatch and specimen wave transit time, facilitating equilibration. The through-thickness modulus $E_{33}$ also increased with strain rate. The failure modes for in-plane compression involved brooming, fibre kinking and delamination. The SHPB tests in the in-plane direction did not result in acceptable specimen equilibrium. However, the general trend from the quasi-static, SHPB and DIHPB tests in the in-plane direction was that peak stress increased with strain rate. Testing at intermediate strain rates, and further investigation of the in-plane SHPB tests to improve equilibration, are intended for future work.

\section{Acknowledgements}

The authors wish to acknowledge ARMSCOR for financial support of research activities at BISRU.

\section{References}

1. P. Pardo, Co-moulding of twintex continuous reinforcement, Technical presentation on Thermoplastic Composites Infrastructure Cooperation Network (2004), www.coronet.eu/uploads/Coronetvetrotex.pdf

2. EireComposites (2011), www . eirecomposites.com

3. W. Hufenbach, A. Hornig, B. Zhou, A. Langkamp, M. Gude, Compos. Sci. Technol. 71, 1110 (2011) 
4. R. Govender, Ph.D. thesis, University of Cape Town (2011)

5. K. Brown, R. Brooks, N. Warrior, Compos. Sci. Technol. 70, 272 (2010)

6. Owens-Corning-Vetrotex Reinforcements, Twintex $T$ PP data sheet (2008)

7. T. Cloete, A. van der Westhuizen, S. Kok, G. Nurick, A tapered striker pulse shaping technique for uniform strain rate dynamic compression of bovine bone, in DYMAT 2009 - 9th International Conference on the Mechanical and Physical Behaviour of Materials Under Dynamic Loading (EDP Sciences, 2009), pp. 901907, www . dymat-proceedings . org

8. R. Govender, L. Louca, A. Fallah, A. Pullen, G. Nurick, J. Compos. Mater. In press (2012)

9. G. Gray III, Mechanical Testing and Evaluation (ASM International, 1999), Vol. 8 of ASM Handbook, chap. Classic Split-Hopkinson Pressure Bar Testing
10. W. Chen, B. Song, Split Hopkinson (Kolsky) Bar (Springer, 2011)

11. P. Follansbee, C. Frantz, J. Eng. Mat. Tech 105, 61 (1983)

12. D. Gorham, J. Phys. E. Sci. Intrum. 16, 477 (1983)

13. D. Gorham, Inst. Phys. Conf. Ser. 47, 16 (1979)

14. D. Gorham, P. Pope, J. Field, Proc. R. Roc. Lond. A8, 153 (1992)

15. J. Lifshitz, H. Leber, Int. J. Impact Engng 15, 723 (1994)

16. L. Yang, V. Shim, Int. J. Impact Engng 31, 129 (2005)

17. M. Tarfaoui, S. Choukri, A. Neme, Compos. Sci. Technol. 68, 477 (2008)

18. B. Gama, J. Gillespie Jr, H. Mahfuz, R. Raines, A. Haque, S. Jeelani, T. Bogetti, B. Fink, J. Compos. Mat. 35, 1201 (2001)

19. I. Daniel, B. Werner, J. Fenner, Compos. Sci. Technol. 71, 357 (2011) 